\title{
Randomized Controlled Trial for an Effect of Green Tea Consumption on Insulin Resistance and Inflammation Markers
}

\author{
Yoko FukINo ${ }^{1}$, Mari SHIMBO ${ }^{1}$, Nobuo AoKI ${ }^{2}$, Tutomu OKUBO ${ }^{3}$ and Hiroyasu Iso ${ }^{4}$ \\ ${ }^{1}$ Department of Nutritional Sciences, School of Food and Nutritional Sciences, University of Shizuoka, \\ 52-1 Yada, Shizuoka 422-8526, Japan \\ ${ }^{2}$ Department of Hygiene, Hamamatsu University School of Medicine, 1-20-1 Handayama, \\ Hamamatsu 431-3192, Japan \\ ${ }^{3}$ Bio Nutrition Division, Taiyou Kagaku Co., Ltd., 1-3-1 Takaramachi, Yokkaichi 510-0844, Japan \\ ${ }^{4}$ Public Health, Department of Social and Environmental Medicine, Graduate School of Medicine, \\ Osaka University, 2-2 Yamadaoka, Suita, Osaka 565-0871, Japan
}

(Received August 17, 2004)

\begin{abstract}
Summary To study the effects of the intake of green tea and polyphenols, which are a component of green tea, on insulin resistance and systemic inflammation, a randomized controlled trial was conducted on 66 patients aged 32-73 y (53 males and 13 females) with borderline diabetes or diabetes. Subjects in the intervention group were asked to take a packet of green tea extracts/powder containing $544 \mathrm{mg}$ polyphenols ( $456 \mathrm{mg}$ catechins) daily, which was a dose that could be taken without difficulty, and were asked to divide the green tea extracts/powder in a packet into 3 or 4 fractions dissolved in hot water everyday and to take a fraction after every meal or snack for $2 \mathrm{mo}$, in addition to daily food intake. The subjects in the control group were simply followed. To calculate the level of green tea polyphenol intake that the subject usually drank at home, the subject was asked to taste 3 teas of different strengths $(1,2$ and 3\%) and the tea that was closest to the one that the subject drank at home, was selected by each subject. After 2 mo, the mean daily polyphenol intake in the intervention group was $747 \mathrm{mg}$, which was significantly higher than that of $469 \mathrm{mg}$ in the control group. In the intervention group, the body weight, BMI, systolic and diastolic blood pressures, blood glucose level, $\mathrm{Hb} \mathrm{A}_{1 \mathrm{c}}$ level, insulin level and HOMA index after taking the supplementation for $2 \mathrm{mo}$, were lower than the respective value before intervention; however, these parameters in the intervention group at 2 mo did not significantly differ from those in the control group. Within the intervention group, changes in insulin level tended to be associated with changes in polyphenol intake. In addition, changes in BMI were associated with changes in blood glucose level and insulin level. In conclusion, the daily supplementary intake of $500 \mathrm{mg}$ green tea polyphenols did not have clear effects on blood glucose level, $\mathrm{Hb} \mathrm{A_{1c }}$ level, insulin resistance or inflammation markers. The positive correlation between the level of polyphenol intake and insulin level warrants further studies on the effect of green tea on insulin resistance.
\end{abstract}

Key Words green tea consumption, polyphenol, fasting blood glucose, insulin resistance, randomized controlled trial

Green tea contains a variety of compounds including polyphenols, caffeine, vitamin $\mathrm{C}$ and carotene. To date, there have been reports on the physiological effects of green tea including its anti-cancer properties (1-7), anti-oxidant properties $(8,9)$, and anti-bacterial properties (10-12). Green tea has been reported to reduce the serum cholesterol level $(13,14)$, body weight, body mass index (BMI), body fat (15-17), and blood glucose level (18), and green tea is expected to show preventive effects on the development of life style-related diseases. However, nutritional and epidemiological studies on the health effects of green tea consumption in humans are scarce, and it is not clear whether green tea can prevent the development of diabetes and cardiovascular diseases.

E-mail: fukino@u-shizuoka-ken.ac.jp
Among the polyphenols (catechins) in green tea, epicatechin gallate (ECG) and epigalocatechin gallate (EGCG) strongly inhibit the activity of saccharolytic enzymes, i.e., $\alpha$-amylase and sucrose. It has been suggested that drinking green tea interferes with the absorption of sugars from the alimentary tract, thus attenuating high blood glucose level (18-20). Furthermore, the polyphenols in green tea have anti-oxidant activity towards low-density lipoprotein (LDL)-cholesterol $(21,22)$.

In our previous cross-sectional studies, we found that green tea consumption was negatively associated with serum lipids, liver dysfunction, and the blood glucose level $(23,24)$. In addition, our preliminary uncontrolled trial on borderline diabetic patients suggested that green tea consumption reduces the blood glucose 
and hemoglobin $(\mathrm{Hb}) \mathrm{A}_{1 \mathrm{c}}$ levels, as well as blood pressure, total cholesterol level and body fat (25). These studies suggest that green tea may be effective in preventing the development of not only diabetes but also cardiovascular diseases.

The level of high-sensitivity C-reactive protein (hsCRP) has been recognized as a sensitive biomarker of inflammation and a risk factor for diabetes and cardiovascular diseases $(26,27)$. Therefore, investigation of the effect of consumption of green tea and its constituent polyphenols on blood glucose, insulin level and insulin resistance and hs-CRP level is expected to provide important clues in the prevention of diabetes and cardiovascular diseases.

A recent population-based study indicated an increase in the prevalence of diabetes (28), as well as that for borderline type diabetes or glucose intolerance among Japanese (29). Thus, it is desirable to investigate the effect of green tea consumption on insulin resistance and inflammation markers in diabetic patients and borderline diabetic patients, but such studies have been scarce. In this study, we analyzed the effects of green tea consumption on the blood glucose level, insulin level, insulin resistance as evaluated by the HOMA index (30), hemoglobin $A_{1 c}$ level, and hs-CRP level in a randomized controlled trial of men and women with diabetes or borderline diabetes. Supplementation of green tea was performed using green tea extract powder that contained $544 \mathrm{mg}$ of polyphenols.

\section{PATIENTS AND METHODS}

Patients, method of study and term of study. We determined the period of intervention as 2 mo because previous studies showed that 1-mo supplementation of $400 \mathrm{mg} / \mathrm{d}$ green tea polyphenol induced a significant reduction of methylguanidine, a marker of biological antioxidant (31), and that supplementation of $588 \mathrm{mg} /$ $\mathrm{d}$ catechins induced a significant weight reduction (15) after 1 and 3 mo.

The subjects were residents of communities on the eastern side of Shizuoka Prefecture, Japan, who had a fasting blood glucose level of $\geqq 110 \mathrm{mg} / \mathrm{dL}$ or a nonfasting blood glucose level $\geqq 140 \mathrm{mg} / \mathrm{dL}$ in recent health check-ups of communities and companies. We asked them to participate in the study and obtained informed consent from 56 males and 14 females aged 32-73 y. Excluding those individuals who dropped out of the study and those who had eaten breakfast on the morning of baseline data sampling, the subjects consisted of 53 males and 13 females. This study was approved by the Research Ethics Committee of University of Shizuoka.

The baseline sampling was performed in late February to early March 2003. The subjects were asked not to eat breakfast on the morning of the baseline data sampling. The subjects were randomly divided into the intervention group who received the supplementation of green tea extract/powder, or the control group who did not receive the supplementation. The supplement was made of a mixture of green tea extract and green tea powder at a ratio of $9: 1$, and one packet contained $544 \mathrm{mg}$ polyphenols (456 mg catechin), which could be consumed daily without difficulty. The green tea powder was specifically prepared courtesy of Taiyou Kagaku Co., Ltd. (Yokkaichi, Mie, Japan) in accordance with our order.

The subjects in the Intervention group took one packet of the green tea extract/powder per day. Each subject in the Intervention group was asked to dissolve 1/3-1/4 content of the packet in hot water and drink it after every meal or snack for a period of 2 mo. The subjects in both intervention and control groups were asked to come in for the second data sampling in early June 2003. The same data as those in the first sampling were collected, and the changes in various biomarkers were analyzed.

Biomarkers. We measured the blood pressure, height, weight, fasting blood glucose level, blood insulin level, and hemoglobin $A_{1 c}$ level. We conducted questionnaires on the subjects' health, lifestyle, and nutrition. We also conducted a questionnaire on the strength of green tea that the subject usually drank and the frequency of green tea consumption. Biochemical tests were performed in the laboratory of the Osaka Medical Center for Health Science and Promotion.

The body mass index (BMI) was calculated as body weight $(\mathrm{kg})$ divided by the square of the height $(\mathrm{m})^{2}$. The HOMA index was calculated as fasting blood glucose level $(\mathrm{mg} / \mathrm{dL})$ multiplied by the fasting insulin level $(\mu \mathrm{U} / \mathrm{mL})$ divided by 405 .

Measurement of the level of green tea polyphenols and calculation of polyphenol intake. The polyphenol content in green tea extract/powder was measured by colorimetry with ferric tartrate reagent (32) as described below.

The sample of green tea extract/powder ( $W$, about $30 \mathrm{mg}$ ) was suspended in $50-60 \mathrm{~mL}$ of deionized water in a $100 \mathrm{~mL}$ measuring flask, and dissolved by placing the flask in a hot water bath at a temperature of above $80^{\circ} \mathrm{C}$. After cooling, the volume in the flask was adjusted to $100 \mathrm{~mL}$ and the solution was filtered. The filtrate was obtained and used in the following experiment.

Five milliliters of the sample solution and $5 \mathrm{~mL}$ of ferric tartrate reagent were placed in a flask, and the volume was adjusted to exactly $25 \mathrm{~mL}$ by adding phosphate buffer. This was mixed well for coloration. After coloration, the concentration of polyphenols was measured by colorimetry at a wavelength of $540 \mathrm{~nm}$, and a calibration curve was obtained using water as the control. This procedure was repeated with ethyl gallate as the standard sample and a calibration curve was plotted. The concentration $(C)$ of ethyl gallate in a sample was determined from this calibration curve, and the total content of polyphenols in the sample was determined by the following equation:

Total polyphenol content $(\%)=(C / W) \times 1.5 \times 100$, The daily intake of green tea was determined by the number of cups of green tea that the subject usually drank and the volume of the cup that the subject used. 
For the subjects in the intervention group, the amount of polyphenols in the supplement was added. The strength of green tea that the subject usually drank was judged by administering a tasting test of 3 levels of strength of green tea, i.e., 1, 2, and 3\%, which were prepared by extracting a given amount of tea in hot water at $85^{\circ} \mathrm{C}$ for $1 \mathrm{~min}$.

Statistical analysis. The significance of differences in mean values and proportions of parameters between the intervention and control groups was assessed using Student's $t$-test and the chi-square test, respectively. The relationship between the level of polyphenol intake and BMI or biochemical parameters was examined by linear regression analysis, adjusted for age. The significance level was set at $p<0.05$.

\section{RESULTS}

Table 1 shows the baseline characteristics of the intervention and control groups. The ratio of males to females was $4: 1$ in both groups. There were no significant differences in age or other baseline characteristics between the two groups.

Table 2 summarizes the data on polyphenol intake and data from the physical and laboratory examinations in the intervention group after 2 mo of intervention and the control group. The level of polyphenol intake was $747 \mathrm{mg} / \mathrm{d}$ in the intervention group and $469 \mathrm{mg} / \mathrm{d}$ in the control group, showing a significant difference. However, the body weight, BMI, systolic and diastolic blood pressures, blood glucose level, $\mathrm{Hb} \mathrm{A}_{1 \mathrm{c}}$ level, HOMA index and insulin level in the intervention group at 2 mo did not significantly differ from the respective parameter in the control group. The hs-CRP level tended to be higher in the intervention group at 2 mo than in the control group $(p=0.06)$.

Figures 1-6 show graphs of the change in polyphenol intake versus the changes in the insulin level (Fig. 1), blood glucose level (Fig. 2), HOMA index (Fig. 3), Hb $A_{1 c}$ level (Fig. 4), hs-CRP level (Fig. 5) and BMI (Fig. 6) in June 2003, among the subjects in the intervention

Table 1. Baseline characteristics of intervention and control groups.

\begin{tabular}{lcc}
\hline \multicolumn{1}{c}{ Baseline variable } & $\begin{array}{c}\text { Intervention } \\
(n=33)\end{array}$ & $\begin{array}{c}\text { Control } \\
(n=33)\end{array}$ \\
\hline Age, $\mathrm{y}$ & $53.5 \pm 8.5$ & $53.5 \pm 7.5$ \\
Men, \% & 81.9 & 78.8 \\
Weight, kg & $68.2 \pm 14.0$ & $69.8 \pm 11.8$ \\
Body mass index, $\mathrm{kg} / \mathrm{m}^{2}$ & $25.5 \pm 4.8$ & $25.9 \pm 3.9$ \\
Systolic blood pressure, $\mathrm{mmHg}$ & $139.3 \pm 15.7$ & $138.6 \pm 18.2$ \\
Diastolic blood pressure, $\mathrm{mmHg}$ & $92.5 \pm 11.1$ & $87.8 \pm 11.5$ \\
Fasting serum glucose, $\mathrm{mg} / \mathrm{dL}$ & $135.0 \pm 59.3$ & $140.2 \pm 44.5$ \\
Hemoglobin $\mathrm{A}_{1 \mathrm{c}}, \%$ & $6.2 \pm 1.9$ & $6.1 \pm 1.3$ \\
Fasting serum insulin, $\mu \mathrm{U} / \mathrm{mL}$ & $8.7 \pm 6.9$ & $10.3 \pm 9.7$ \\
HOMA & $3.0 \pm 2.7$ & $3.7 \pm 4.2$ \\
C-reactive protein, $\mu \mathrm{g} / \mathrm{dL}$ & $118 \pm 121$ & $115 \pm 158$ \\
Polyphenol intake, $\mathrm{mg} / \mathrm{d}$ & $445 \pm 263$ & $306 \pm 169$ \\
Ethanol intake, $\mathrm{g} / \mathrm{d}$ & $29.3 \pm 26.2$ & $22.2 \pm 21.7$ \\
\hline
\end{tabular}

Values are mean \pm SD or percentage.
Table 2. Changes in weight, body mass index, systolic blood pressure, diastolic blood pressure, polyphenol intake, serum glucose, insulin, hemoglobin $A_{1 c}$, HOMA, and CRP.

\begin{tabular}{|c|c|c|}
\hline & Baseline & After 2 mo \\
\hline \multicolumn{3}{|l|}{ Weight, kg } \\
\hline Intervention & $68.2 \pm 14.0$ & $67.4 \pm 13.3$ \\
\hline Control & $69.8 \pm 11.8$ & $69.4 \pm 11.5$ \\
\hline$p$ & 0.63 & 0.52 \\
\hline \multicolumn{3}{|c|}{ Body mass index, $\mathrm{kg} / \mathrm{m}^{2}$} \\
\hline Intervention & $25.5 \pm 4.8$ & $25.2 \pm 4.5$ \\
\hline Control & $25.9 \pm 3.9$ & $25.8 \pm 3.9$ \\
\hline$p$ & 0.71 & 0.58 \\
\hline \multicolumn{3}{|c|}{ Systolic blood pressure, $\mathrm{mmHg}$} \\
\hline Intervention & $139.3 \pm 15.7$ & $131.6 \pm 20.8$ \\
\hline Control & $138.6 \pm 18.2$ & $129.2 \pm 19.0$ \\
\hline$p$ & 0.87 & 0.62 \\
\hline \multicolumn{3}{|c|}{ Diastolic blood pressure, mmHg } \\
\hline Intervention & $92.5 \pm 11.1$ & $83.3 \pm 12.6$ \\
\hline Control & $87.8 \pm 11.5$ & $83.2 \pm 15.3$ \\
\hline$p$ & 0.10 & 0.99 \\
\hline \multicolumn{3}{|c|}{ Fasting serum glucose, mg/dL } \\
\hline Intervention & $135.0 \pm 59.3$ & $128.8 \pm 46.5$ \\
\hline Control & $140.2 \pm 44.5$ & $129.8 \pm 29.2$ \\
\hline$p$ & 0.69 & 0.91 \\
\hline \multicolumn{3}{|c|}{ Hemoglobin $\mathrm{A}_{1 \mathrm{c}}, \%$} \\
\hline Intervention & $6.2 \pm 1.9$ & $6.0 \pm 1.9$ \\
\hline Control & $6.1 \pm 1.3$ & $6.1 \pm 1.4$ \\
\hline$p$ & 0.78 & 0.74 \\
\hline \multicolumn{3}{|c|}{ Fasting serum insulin, $\mu \mathrm{U} / \mathrm{mL}$} \\
\hline Intervention & $8.7 \pm 6.9$ & $7.4 \pm 6.8$ \\
\hline Control & $10.3 \pm 9.7$ & $6.9 \pm 4.1$ \\
\hline$p$ & 0.45 & 0.73 \\
\hline \multicolumn{3}{|l|}{ HOMA } \\
\hline Intervention & $3.0 \pm 2.7$ & $2.4 \pm 2.4$ \\
\hline Control & $3.7 \pm 4.2$ & $2.2 \pm 1.4$ \\
\hline$p$ & 0.40 & 0.70 \\
\hline \multicolumn{3}{|c|}{ C-reactive protein, $\mu \mathrm{g} / \mathrm{dL}$} \\
\hline Intervention & $118 \pm 121$ & $130.0 \pm 189$ \\
\hline Control & $115 \pm 158$ & $65 \pm 51$ \\
\hline$p$ & 0.94 & 0.06 \\
\hline \multicolumn{3}{|c|}{ Polyphenol intake, mg/d } \\
\hline Intervention & $445 \pm 263$ & $747 \pm 220$ \\
\hline Control & $306 \pm 169$ & $469 \pm 340$ \\
\hline$p$ & 0.02 & $<0.01$ \\
\hline
\end{tabular}

Values are mean \pm SD.

group. Age-adjusted mean changes (standard errors) associated with a $100 \mathrm{mg} / \mathrm{d}$ increase of polyphenol intake were $0.41(0.22), p=0.07$ for fasting serum insulin, $-1.37(1.98), p=0.50$ for fasting serum glucose, 0.11 (0.10), $p=0.25$ for HOMA index, -0.08 (0.06), $p=0.16$ for hemoglobin $A_{1 c}, 17.66$ (14.74), $p=0.24$ for hs-CRP, -0.007 (0.05), $p=0.89$ for BMI. There tended to be a positive correlation between the changes of polyphenol intake and insulin level. But there were no significant relationships between the changes in polyphenol intake and each BMI, blood glucose level, $\mathrm{Hb} \mathrm{A}_{1 \mathrm{c}}$ level, HOMA index nor hs-CRP level.

Figures 7 and 8 show the relationships between the change in BMI and the change in blood glucose level or 


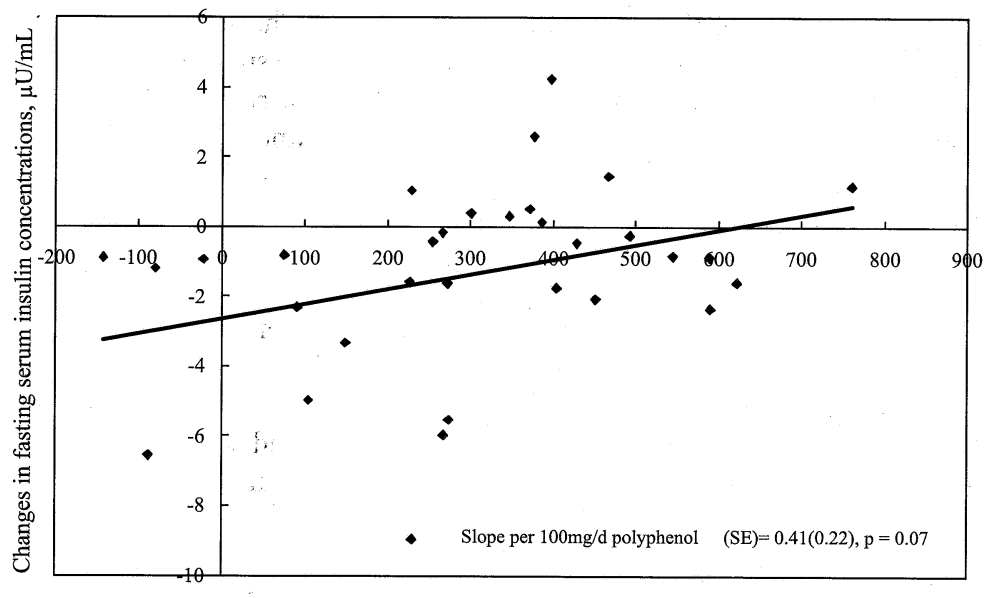

Changes in polyphenol intake, $\mathrm{mg} / \mathrm{d}$

Fig. 1. The relationship between the changes in polyphenol intake and the changes in fasting serum insulin levels among the subjects in the intervention group.

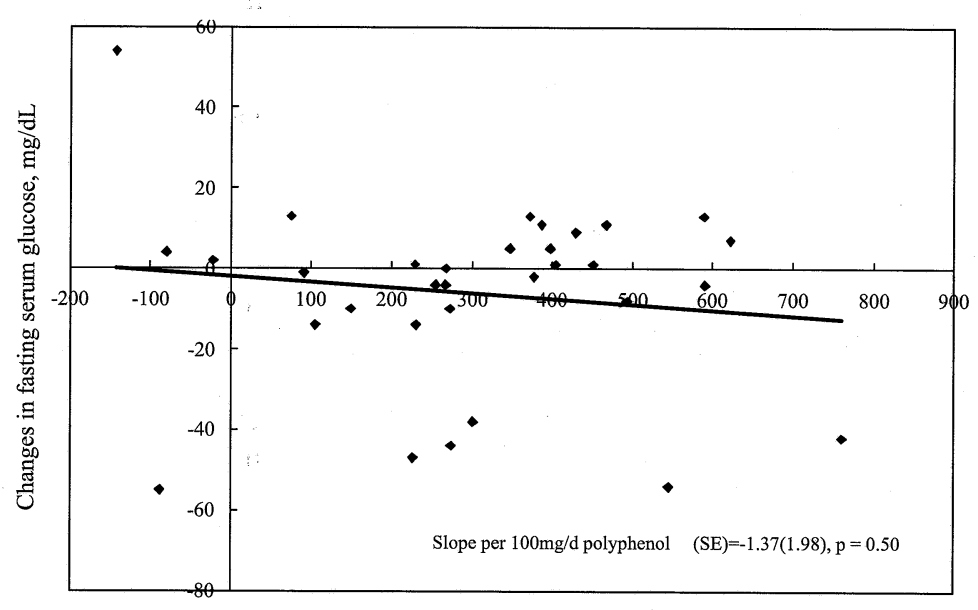

Changes in polyphenol intake, $\mathrm{mg} / \mathrm{d}$

Fig. 2. The relationship between the changes in polyphenol intake and the changes in fasting serum glucose levels among the subjects in the intervention group.

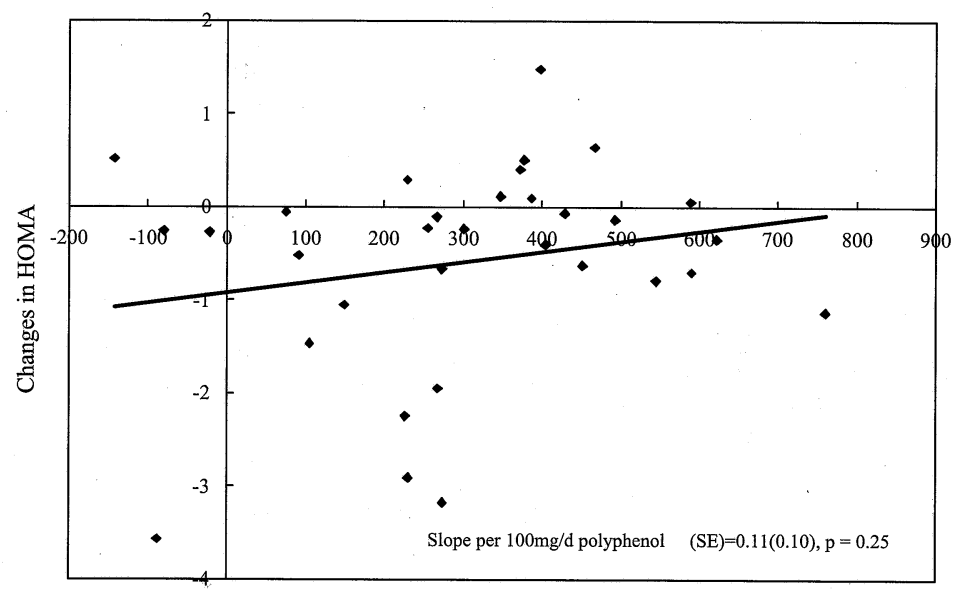

Changes in polyphenol intake, $\mathrm{mg} / \mathrm{d}$

Fig. 3. The relationship between the changes in polyphenol intake and the changes in HOMA index among the subjects in the intervention group. 


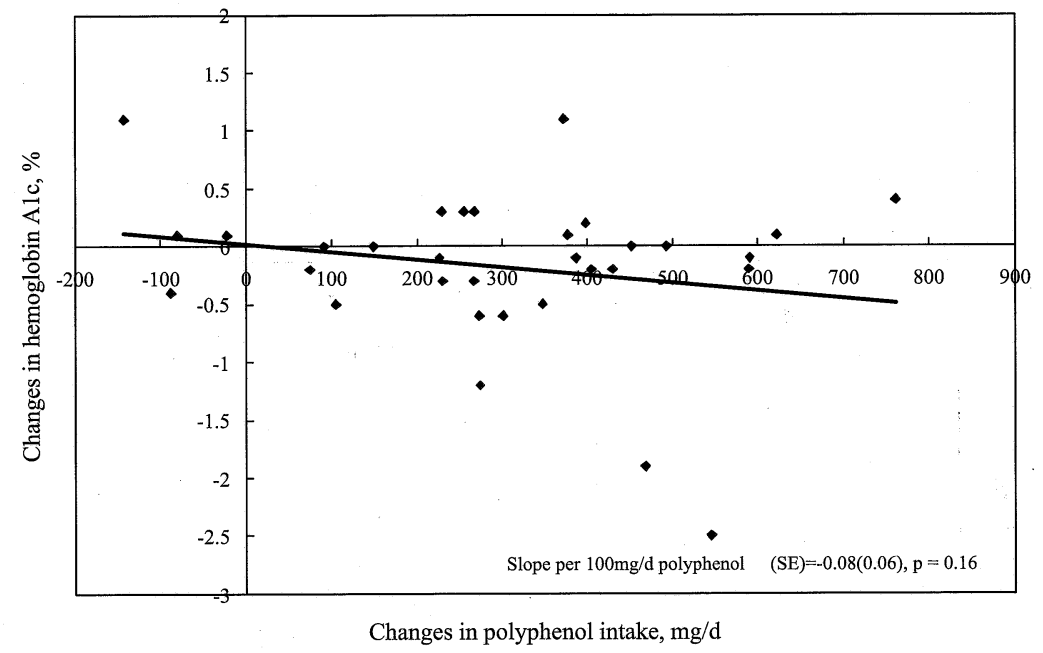

Fig. 4. The relationship between the changes in polyphenol intake and the changes in fasting serum hemoglobin $A_{1 c}$ among the subjects in the intervention group.

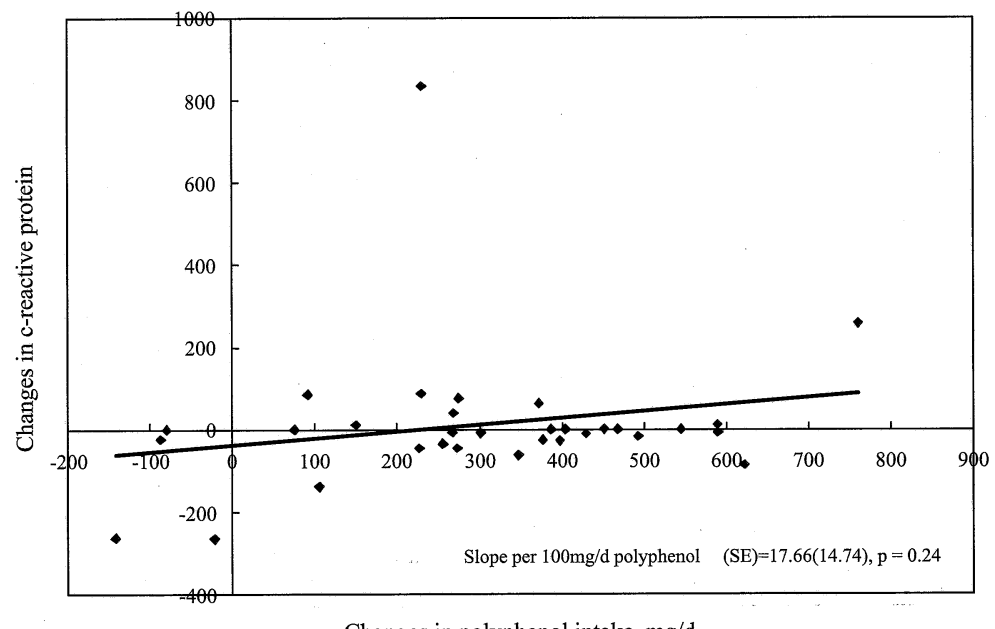

Changes in polyphenol intake, $\mathrm{mg} / \mathrm{d}$

Fig. 5. The relationship between the changes in polyphenol intake and the changes in fasting serum C-reactive protein among the subjects in the intervention group.

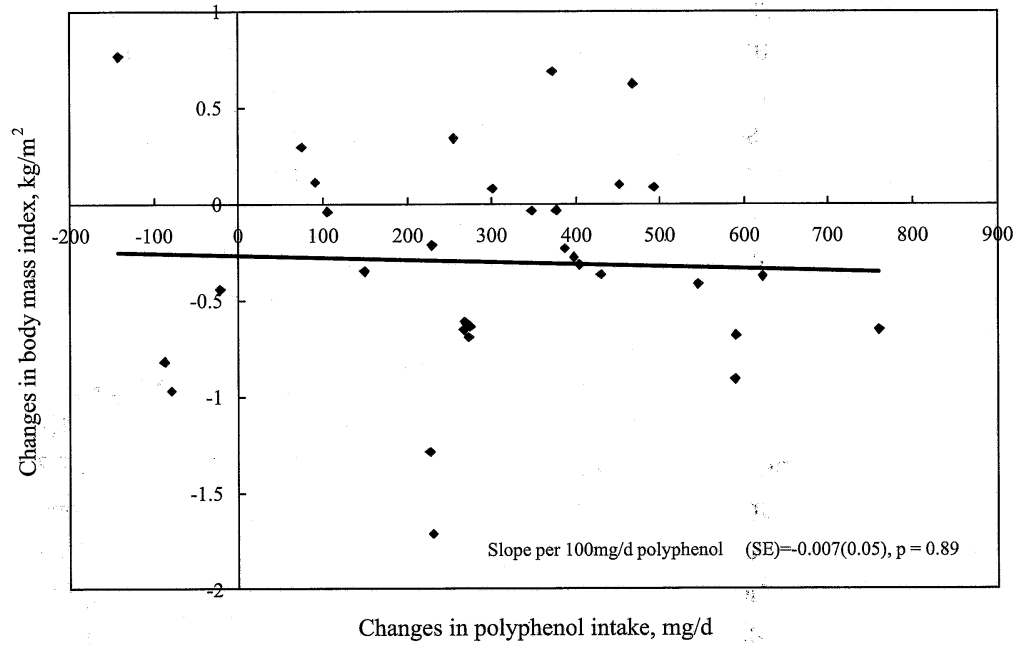

Fig. 6. The relationship between the changes in polyphenol intake and the changes in body mass index among the subjects in the intervention group. 


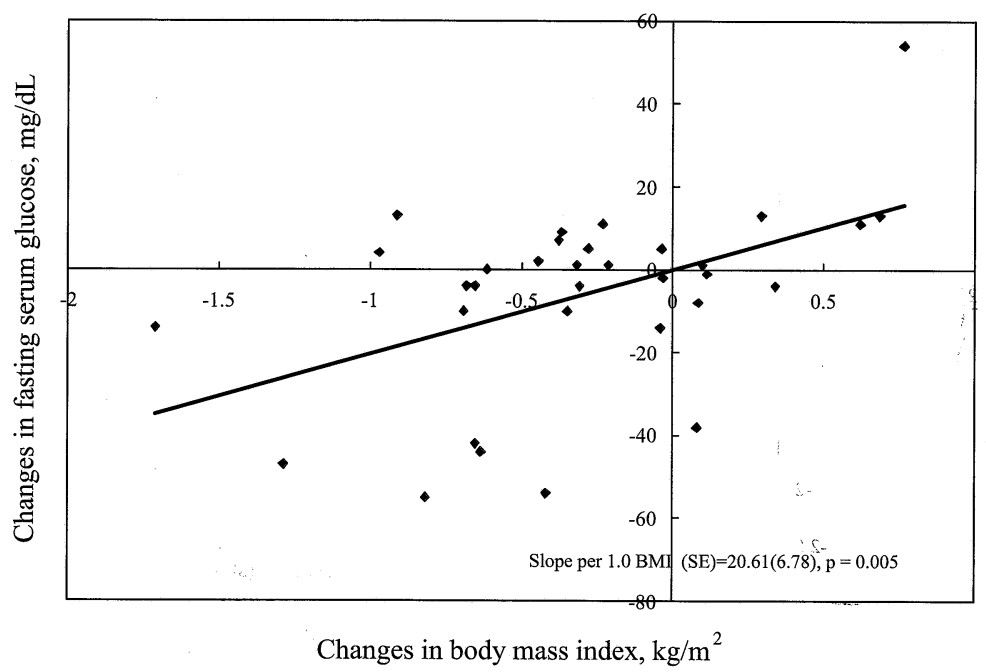

Fig. 7. The relationship between the changes in body mass index and the changes in fấsting serum glucose among the subjects in the intervention group.

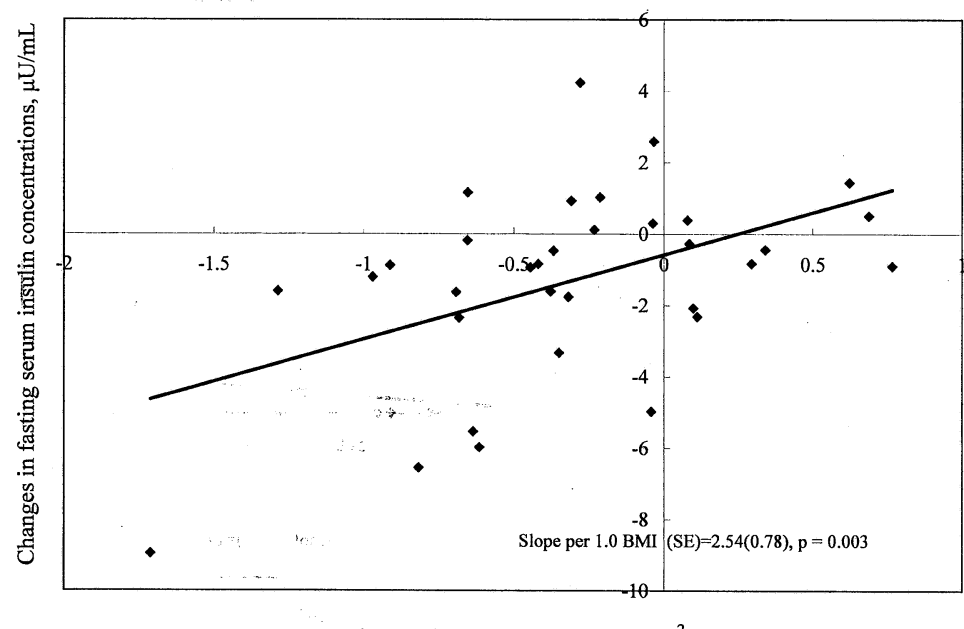

Fig. 8 . The relationship between the changes in body mass index and the changes in fasting serum insulin levels among the subjects in the intervention group.

insulin level, respectively, among the subjects in the intervention group. Mean changes (standard errors) associated with a one-Unit increase of BMI $\left(\mathrm{kg} / \mathrm{m}^{2}\right)$ were 20.61 (6.78), $p=0.005$ for fasting serum glucose $(\mathrm{mg} / \mathrm{mL})$ and $2.54(0.78), p=0.003$ for fasting serum insulin. There were positive correlations of the change in BMI with the changes in blood glucose level and insulin level.

\section{DISCUSSION}

Few studies have analyzed the relationship between the level of consumption of green tea polyphenols and physical biomarkers by measuring the precise amount of intake of green tea polyphenols (catechins). In this study, we asked each subject to rate the strength of green tea that he/she usually drank by choosing from three concentrations of green tea, to ensure higher precision in our calculation of the daily level of polyphenol intake. Furthermore, we asked the subjects the size of the teacups that they usually used, and attempted to estimate the level of polyphenol intake more precisely.
The-mean baseline BMI was 25.5 in the intervention group and 25.9 in the control group. More than $50 \%$ of the subjects in each group were overweight. Furthermore, the mean systolic blood pressure among all subjects was at the upper limit of normal, and the mean diastolic blood pressure was at the upper limit of normal or hypertensive. The mean blood glucose level and mean $\mathrm{Hb} \mathrm{A}_{\mathrm{lc}}$ level were also in the range of values for borderline diabetic or diabetic patients. The HOMA index (30), which is a marker of insulin resistance, was $>3.0$ in both groups, indicating that most of the subjects had insulin resistance (33-36).

In this study, we administered a supplement of green tea polyphenols for 2 mo to the subjects in the intervention group. Mean body weight, BMI, blood glucose level, $\mathrm{Hb} \mathrm{A}_{1 \mathrm{c}}$ level, insulin level or HOMA index in the intervention group at 2 mo did not differ significantly from those in the control group because of their similar reduction. Therefore, the expected beneficial effects of consumption of green tea extract/powder were not observed. 
The reductions in cardiovascular parameters observed in both the intervention and control groups may suggest that the subjects in the control group became more sensitive about improving their health in daily life. Another reason for the lack of significant differences between the two groups may be the lack of restrictions on drinking green tea in the control group.

The hs-CRP level tended to increase in the intervention group 2 mo after green tea supplementation and decreased in the control group, and the intervention group tended to have a higher mean hs-CRP level than the control group. However, the observed difference was interpreted as incidental because there was no significant correlation between the level of polyphenol intake and the hs-CRP level in either group.

Next, by analyzing the relationship between the level of polyphenol intake and biochemical markers among all of the subjects, we found that there tended to be a positive correlation between the level of polyphenol intake and the insulin level.

It has been reported in animal experiments that green tea polyphenols increase insulin activity (37); however, no similar study has been conducted in humans. If an increase in insulin activity does in fact occur in humans, we would expect that consumption of green tea polyphenols would lower the blood insulin concentration and HOMA index. However, the results of this study did not support this hypothesis.

The change in BMI was correlated with the change in blood glucose level among the subjects in the intervention group. However, we were unable to reach the conclusion that long-term drinking of green tea reduces body weight and thus improves the blood glucose level. Tsuchida et al. (15) studied persons with an average BMI of $24-30 \mathrm{~kg} / \mathrm{m}^{2}$ who were given a daily dose of $588 \mathrm{mg}$ tea catechins and reported that the average body weight of the intervention group $(n=39)$ was $0.54 \mathrm{~kg}$ less after $4 \mathrm{wk}$ and $1.69 \mathrm{~kg}$ less after $12 \mathrm{wk}$ compared with the the control group $(n=41)$.

In conclusion, in this randomized controlled trial, we found that a $544 \mathrm{mg} / \mathrm{d}$ supplemental intake of green tea polyphenols for 2 mo did not significantly improve the blood glucose level, $\mathrm{Hb} \mathrm{A}_{1 \mathrm{c}}$ level, insulin resistance nor the hs-CRP level among diabetic and borderline diabetic patients. The positive correlation between the level of polyphenol intake and insulin level warrants further studies on the effect of green tea on insulin resistance.

\section{Acknowledgments}

We express our sincere gratitude to Professor Mamoru Isemura, Department of Food and Nutritional Science, University of Shizuoka for his suggestions and assistance with this study. In addition, we thank the Section of Health and Welfare, Fujikawa-cho, Shizuoka, officials of organizations and industries in the cities of Shizuoka, Shimizu, and Yaizu, The Osaka Medical Center for Health Science and Promotion, and other institutions, and all the participants for their cooperation.

This work was partly supported by Grant-in-Aid No. 14570348, 2002-2003, from the Ministry of Educa- tion, Culture, Sports, Science and Technology of Japan.

\section{REFERENCES}

1) Muramatsu K, ed. 1994. Science of Tea. Asakura Press, Tokyo (in Japanese).

2) Ito T, Sasaki R. 1995. Green tea and cancer prevention. Modern Med Sci 42: 567-574 (in Japanese).

3) Hara Y, Matsuyama S, Nakamura K. 1989. Anti-tumor activity of tea catechins. Nippon Eiyou Shokuryou Gakkaishi (J Jpn Soc Nutr Food Sci) 42: 39-45 (in Japanese).

4) Suganuma M, Okabe S. 1996. Cancer prevention by green tea. Igaku no Ayumi 176: 760-761 (in Japanese).

5) Isemura M, Suzuki Y, Satoh K, Narumi K, Motomiya M. 1993. Effects of catechins on the mouse lung carcinoma cell adhesion to the endothelial cells. Cell Biol Int 17: 559-564.

6) Imai K, Suga K, Nakachi K. 1997. Cancer-preventive effects of drinking green tea among a Japanese population. Prev Med 26: 769-775.

7) Dreosti IE, Wargovich MJ, Yang CS. 1997. Inhibition of carcinogenesis by tea: the evidence from experimental studies. Crit Rev Food Sci Nutr 37: 761-770.

8) Yokozawa T, Cho EJ, Hara Y, Kitani K. 2000. Antioxidative activity of green tea treated with radical initiator 2,2'-azobis(2-amidinopropane) dihydrochloride. J Agric Food Chem 48: 5068-5073.

9) Kawase M, Wang R, Shiomi T, Saijo R, Yagi K. 2000. Antioxidative activity of (-)-epigallocatechin-3-(3"-Omethyl)gallate isolated from fresh tea leaf and preliminary results on its biological activity. Biosci Biotechnol Biochem 64: 2218-2220.

10) Amarowicz R, Pegg RB, Bautista DA. 2000. Antibacterial activity of green tea polyphenols against Escherichia coli K 12. Nahrung 44: 60-62. No abstract available.

11) Sakanaka S, Kim M, Taniguti M, Yamamoto T. 1989. Antibacterial substances in Japan green tea extract against Streptococcus mutants, a cariogenic bacterium. Agric Biol Chem 53: 2307-2311.

12) Mabe K, Yamada M, Oguni I, Takahashi T. 1999. In vitro and in vivo activities of tea catechins against Helicobacter pylori. Antimicrob Agents Chemother 43: 17881791.

13) Muramatsu K, Fukuyo M, Hara Y. 1986. Effect of green tea catechins on plasma cholesterol level in cholesterolfed rats. J Nutr Sci Vitaminol 32: 613-622.

14) Imai K, Nakachi K. 1995. Cross sectional study of effects of drinking green tea on cardiovascular and liver diseases. BMJ 310 (6981): 693-696.

15) Tsuchida T, Itakura H, Nakamura H. 2002. Reduction of body fat in humans by long-term ingestion of catechins. Progress Med 22: 2189-2203 (in Japanese).

16) Nagao T, Megro S, Soga S, Otsuka A, Tomonobu K, Fumoto S, Chikama A, Mori K, Yuzawa M, Watanabe H, Hase T, Tanaka Y, Tokimitsu I, Shimasaki H, Itakura H. 2001. Tea catechins suppress accumulation of body fat in humans. J Oleo Sci 50: 717-728.

17) Hase T, Komine Y, Meguro S, Takeda Y, Takahasi H, Matsui Y, Inaoka S, Katsuragi Y, Tokimitsu I, Shimasaki H, Itakura H. 2001. Anti-obesity effects of tea catechins in humans. J Oleo Sci 50: 599-605.

18) Matsumoto N, Ishigaki F, Ishigaki A, Iwashina H, Hara Y. 1993. Reduction of blood glucose levels by tea catechin. Biosci Biotech Biochem 57: 525-527.

19) Hara Y, Honda M. 1990. The inhibition of $\alpha$-amylase by tea polyphenols. Agric Biol Chem 54: 1939-1945. 
20) Honda M, Hara Y. 1993. Inhibition of rat small intentinal sucrase and $\alpha$-glucosidase activities by tea polyphenols. Biotech Biochem 57: 123-124.

21) Rice-Evans C, Leake D, Bruckdorfer KR, Diplock AT. 1996. Practical approaches to low density lipoprotein oxidation: whys, wherefores and pitfalls. Free Rad Res 25: 285-311.

22) Miura Y, Chiba T, Miura S, Tomita I, Umegaki K, Ikeda M, Tomita T. 2000. Green tea polyphenols (flavan 3-ols) prevent oxidative modification of low density lipoproteins: An ex vivo study in humans. J Nutr Biochem 11: 216-222.

23) Fukino Y, Aoki N, Kato Y, Watanabe C, Nakamura M, Tanimizu T. 1999. Green tea consumption among the elderly, nutrition and health. Kousei No Shihyo 46: 1017 (in Japanese).

24) Fukino Y. 2000. Significance of nutrients and green tea intake to prevent life-style related diseases. Proceedings of the Fourth Shizuoka Forum On Health And Longevity, p 123-128.

25) Fukino Y, Aoki N, Takeshita T, Tojo Y, Okubo Y. 2001. A study on the effects of green tea intake on blood glucose in Shizuoka, Japan. International Conference on O-CHA (Tea) Culture and Science, p 126.

26) Schulze MB, Rimm EB, Li T, Rifai N, Stampfer MJ, Hu FB. 2004. C-reactive protein and incident cardiovascular events among men with diabetes. Diabetes Care 27: 889-894.

27) Nakanishi S, Yamane K, Kamei N, Okubo M, Kohno N. 2003. Elevated C-reactive protein is a risk factor for the development of type 2 diabetes in Japanese Americans. Diabetes Care 26: 2754-2757.

28) Ohmura T, Ueda K, Kiyohara Y, Kato I, Iwamoto H, Nakayama K, Nomiyama K, Ohmori S, Yoshitake T, Shinkawa A, et al. 1993. Prevalence of type 2 (noninsulin-dependent) diabetes mellitus and impaired glu- cose tolerance in the Japanese general population: the Hisayama Study. Diabetologia 36: 1198-1203.

29) Ministry of Health, Welfare and Labor. 2004. The National Survey for Diabetes. (in Japanese).

30) Japan Diabetes Society ed. 2002. Guidelines of Treatment for Diabetes 2002-2003. Bunkodo, Tokyo (in Japanese).

31) Yokozawa T, Oura H, Shibata T, Ishida K, Kaneko M, Hasegawa M, Sakanaka S, Kim M. 1996. Effects of green tea tannin in dialysis patients. J Trad Med 13: 124-131.

32) Iwase K, Ota I, Torii H. 1970. Improvement of official chemical analysis for tea (Part 3). Tea industry technical research. Chagyo Gijutsu Kenkyu 40: 69-73 (in Japanese).

33) The DECODE Study Group on Behalf of the European Diabetes Epidemiology Group. 1999. Glucose tolerance and mortality: comparison of WHO and American Diabetes Association diagnostic criteria. Lancet 354: 617621.

34) McNeely MJ, Boyko EJ, Leonetti DL, Kahn SE, Fujimoto WY. 2003. Comparison of a clinical model, the oral glucose tolerance test, and fasting glucose for prediction of type 2 diabetes risk in Japanese Americans. Diabetes Care 26: 758-763.

35) Mclaughlin T, Abbasi F, Cheal K, Chu J, Lamendolla C, Reaven G. 2003. Use of metabolic markers to identify overweight individuals who are insulin resistant. Ann Intern Med 139: 802-809.

36) Kashiwabara H, Inaba M, Maruno Y, Morita T, Awata T, Negishi K, litaka M, Katayama S. 2000. Insulin levels during fasting and the glucose tolerance test and Homa's index predict subsequent development of hypertension. J Hypertens 18: 83-88.

37) Anderson R, Dolansky MM. 2002. Tea enhances insulin activity. J Agric Food Chem 50: 7182-7186. 